\title{
Cooperative relations and activities in the cluster
}

\author{
J. Vodák, M. Varmus, P. Ferenc, and D. Zraková \\ Faculty of Management Science and Informatics, University of Zilina, \\ Univerzitna 8215/1, 01026 Zilina, Slovakia \\ \{josef.vodak, michal.varmus, patrik.ferenc, diana.zrakova\} \\ efri.uniza.sk
}

\begin{abstract}
To increase the competitiveness of the small businesses are merged into different groups. One of the species of grouping of businesses is a cluster. Various cooperation relations originate between individual organizations in the cluster. These relationships and activities of enterprises based on the focus of the cluster. This article through a general model solution shows the possibilities of the proper functioning of the cluster.
\end{abstract}

Keywords: cooperative relations, cluster, automotive, management, organization.

\section{Introduction}

Nowadays, full of fierce competition we can move forward only with a sufficient dose of a sense of something different, something new and prove to apply it in practice. Basically, the basis for the competitiveness of the company is continuous development and innovation. Such a competitive advantage can also be achieved through either well designed collaboration with stakeholders or by cooperation in the field of the latest trends, in a word, is a cluster.

„Clusters are geographic concentrations of interconnected companies and institutions in a particular field. Clusters encompass an array of linked industries and other entities important to competition." [3]

Based on an analysis of selected clusters in the automotive sector it has been specified the sense of the existence of clusters and activities which the clusters perform. Subsequently, was suggested the general model of managing cluster.

In view of the foregoing, the main aim of this article is to identify new opportunities for strategic direction and improving cooperation structures which have been processed into a uniform general model. New options have been proposed based on the analysis of two real existing and relatively well functioning associations, Automotive Cluster Slovakia (ACS) and Moravian-Silesian Automotive Cluster (MAC). Mentioned clusters were selected based on the similarity of the cluster itself, but also the states on whose territory they operate. 


\section{The reasons for the existence of clusters}

Clusters are recently seen as a means of increasing the innovation performance of which show the increase of the competitiveness of associated enterprises and the whole region. [5]

For small and medium-sized enterprises the clusters represent a means to gain a competitive advantage by strengthening interconnections and relationships. [10]

In general, the sense of cluster is development of new technologies and innovation, development of new products and services, observation and exploration of new trends, but also acquisition of new members from different fields which will bring new knowledge and also the education of employees increased, which is related to attracting new business opportunities. Clusters are also beneficial in achieving costs savings of scale. [13]

The sense of the creation of the association was the promotion and development of its members - improving market conditions for members and increase their competitiveness. Specific meaning of individual association describes their mission (the reason for the existence of the cluster). The mission of ACS is to promote the development of subcontractors in the automotive industry and help to ensure their continued competitiveness at home and abroad through peer grouping of industrial enterprises, universities, scientific research institutions and other entities of the private and public sectors. [14]

MAC's mission is to create conditions and support the competitiveness of the members for the region's sustainable development.

This mission the cluster fulfilled by the realization of a vision to become the integrator companies, educational and research institutions and other stakeholders whose activities support the development of the automotive industry in the region. [8]

\section{Activities of clusters}

According to Chudoba and Svač the exchange and transfer of information as well as their mutual dissemination and sharing are essential activities in the cluster. The authors also reported some cluster activities that have been identified in the ACS.

These activities are:

- $\quad$ training and classification (transfer of know-how and dedicated actions);

- $\quad$ internationalization (collaboration with global markets);

- cooperation with enterprises and educational institutions;

- marketing activities (improvement of image, identity creation and branding, public relations, etc.);

- activity centres of excellence (research, development, tests, exams, projects, etc.);

- $\quad$ information and communication with businesses in finding solutions. [10]

Activities that members of ACS and MAK expect from the association are identical and include: eliminate the disadvantages arising from their size (costs of research and development, marketing, training of staff, differentiation of production), removal to the difficulties in obtaining loans and subsidies, expansion of production for border region, 
the support of members in the research, development and innovation, provision of the know-how, synergies in the implementation of common activities, sharing of services, human resources development. [1, 15]

Activities of clusters processed into a model can be seen in the following figures 1 and 2. Figure 1 shows the activities carried out within the automotive cluster Slovakia.

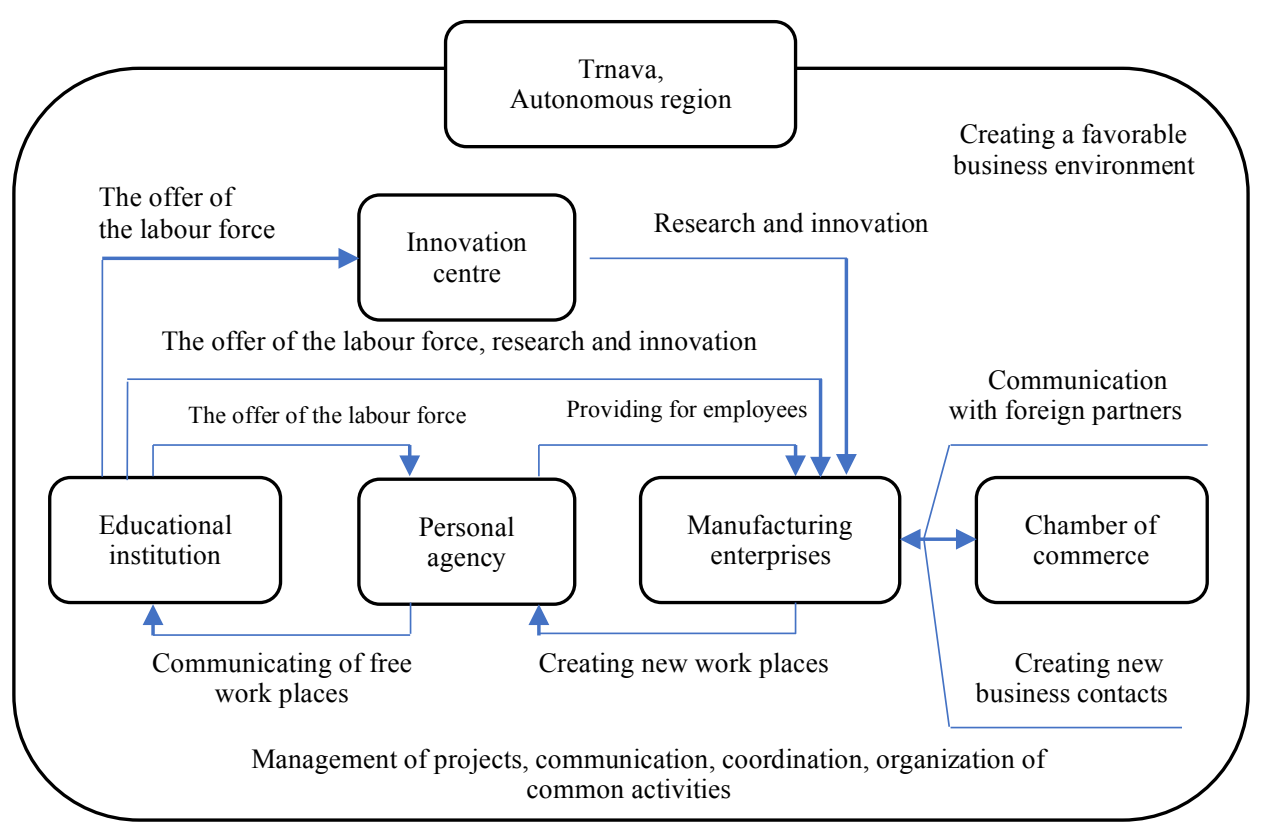

Fig. 1. Automotive Cluster Slovakia

Slovakia Automotive Cluster is regionally oriented. Its scope is mainly in the Trnava region. ACS tries to create a favourable business environment for enterprises. Various cooperation relationships be formed among the organizations in the cluster. Manufacturing companies cooperate with recruitment agencies that give them employees. These agencies gain employees from educational institutions. Educational institutions have a direct relationship with the innovation centres, which in turn cooperate with manufacturing companies. These enterprises have a relationship with the Chamber of Commerce.

The ACS with their activities seeks to fulfil the following objectives: linking production requirements with the academic and scientific-research environment and internationalization in cooperation with foreign companies.

The following figure 2 shows the activities carried out within the Moravian-Silesian automotive cluster. 


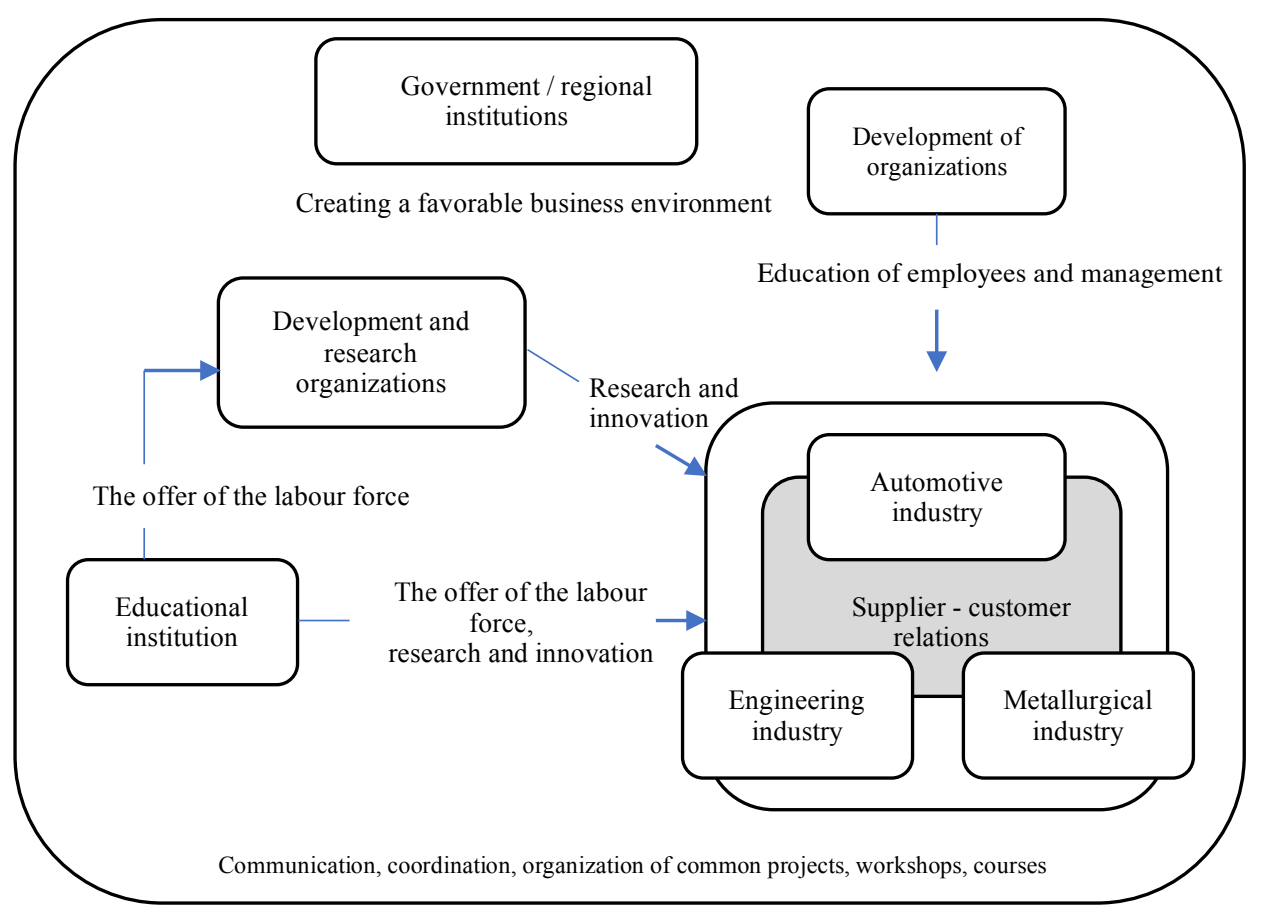

Fig. 2. Moravian-Silesian Automotive Cluster

Moravian-Silesian Automotive Cluster also create for businesses a favorable business environment. However, in this cluster the relationships between individual entities are different than in the ACS. Educational institutions are directly related with research organizations and the whole industry that includes automobile, mechanical and metallurgical industries. Among these components sectors are mutual supplier customer relations. Development and research organizations impact with their activities on the industry and also the possibilities for development organizations in the form of employee training and management of enterprises.

The MAC with their activities seeks to fulfil the following objectives: development of human resources of cluster members and the support of cluster members in the area of research and innovation.

\section{Management and marketing activities within the analysed clusters}

Marketing and management activities in each cluster are important, like in each company. One of the most important management activities, respectively a collection of activities is cooperation. Cluster would not work without cooperation. Thanks to the good cooperation cluster uses all capacities of all associated enterprises. For 
cooperation cluster obtain the innovation capacity, thanks to which it implements science and research and improve competitiveness. Creation projects and laboratory research belong to the second group very important management activities in cluster. The projects represent common activity and the involvement of associations of undertakings in the cluster, so this is a common product that creates a cluster. Projects are often linked to the need of analysing and proposing solutions which implies the needs for research. Marketing and marketing activities in the cluster are aimed at promoting the entire cluster and its individual members not only of regional scope, but especially abroad. Among the most used marketing activities include public relations, participation in conferences, exhibitions and fairs, creation and distribution of promotional materials such as catalogues or brochures. Marketing activities do not have to perform only companies in the cluster but also the other Stakeholder. As an example the booklet that released the Ministry of Economy of the Slovak Republic for support Slovak clusters (for more resources [6]).

\section{Stakeholders and their mutual cooperation}

"Building clusters and networks is particularly important in terms of potential growth interested companies, their education, new opportunities and possibilities for development which may arise in building cooperation. Clusters and networks can be a reaction to the current economic crisis and strengthen the company which act without broad cooperation and partners yet. " [10]

In the framework of mutual cooperation between individual enterprises of the cluster there are formed cooperative relationships with stakeholders. Stakeholders are individuals, groups of persons or organizations that may influence or affect the business, or are affected by the activities of the enterprise. [7,11] Therefore, it can be said that individual companies in the cluster are not only partners, but also stakeholders. To achieve success, you must venture the key stakeholders who can then use to achieve success. [12]

The collaboration with the various stakeholders is one of the core activity for enterprises in the cluster. Thanks to the good control of cooperative relations, the company may achieve the desired success, or elimination of one of their weaknesses (for example, low competitiveness).

The above-mentioned relationship management in the cluster can be difficult for businesses, therefore is to simplify the management of cooperative relations with companies within the cluster and individual stakeholder appropriate to use the DSS (Decision Support System).

To ensure the effective functioning of the competitiveness of joint ventures in the cluster, or entire industries is need to support decision-making by means of IS / ICT. Under conditions of globalization, it is not basically possible to obtain information without the use of IT. Through integrated IT applications it is possible in the area of management, for example: to interconnect IS stakeholders; to ensure the smooth operation of the JIT (Just In Time); link the banks data and knowledge of cooperation partners; to ensure product and service innovation; able to streamline and speed up a slow human labour; thanks to integrated IT applications it is possible the better 
coordinate geographically decentralized operations, which is in the case of clusters very important. [9]

According to Škorecová, in a modern economy is lately recommendation to minimize competitive clashes and neutrality of small and medium-sized enterprises, secure by strategic alliances. These strategic alliances are based on information and communication processes, which shows the imperative need to IS / ICT. From the above it can be concluded that nowadays there should be an emphasis on cooperation and the creation of competitive associations of small and medium-sized enterprises that support its operation through the IS / ICT. Because the Alliance is an association of undertakings like the cluster, it also implies for the cluster to use support their decisions by IS / ICT, respectively directly with decision support systems (Decision Support Systems - DSS). [9]

According to Shim et al. DSS is an interactive information system that supports the decisions by solution of well-structured and unstructured problems.

The output from the DSS are various variants of solutions that may be in the form of the model, reports, graphs, etc. [2]

In spite of the fact that DSS is made up of models, a variety of structured and unstructured data, databases where this information is located, but also the people and the various processes it can be concluded that DSS can support decision making in the cluster as a whole. So if DSS associates models, people, databases, etc., it can be able to associate also associated enterprises in the cluster and support their common decision. [4]

\section{Models of cooperative connection in the cluster}

Based on previous findings, the model of collaborative links within the cluster was proposed. This model was named as Model six components because of the identified information was identified 6 main components affecting the cluster as a whole. The main idea of this model is connection factors Porter's diamond and main components of the cluster. Porter's diamond reflects the effects of four components (firm strategy, structure and rivalry, demand conditions, factor conditions, related and supporting industries) with respect to the geographical coverage of the cluster. Furthermore, the model consists of 6tich components (main components of the cluster). These components have mutual relations and they are also influenced by factors Porter's diamond. 


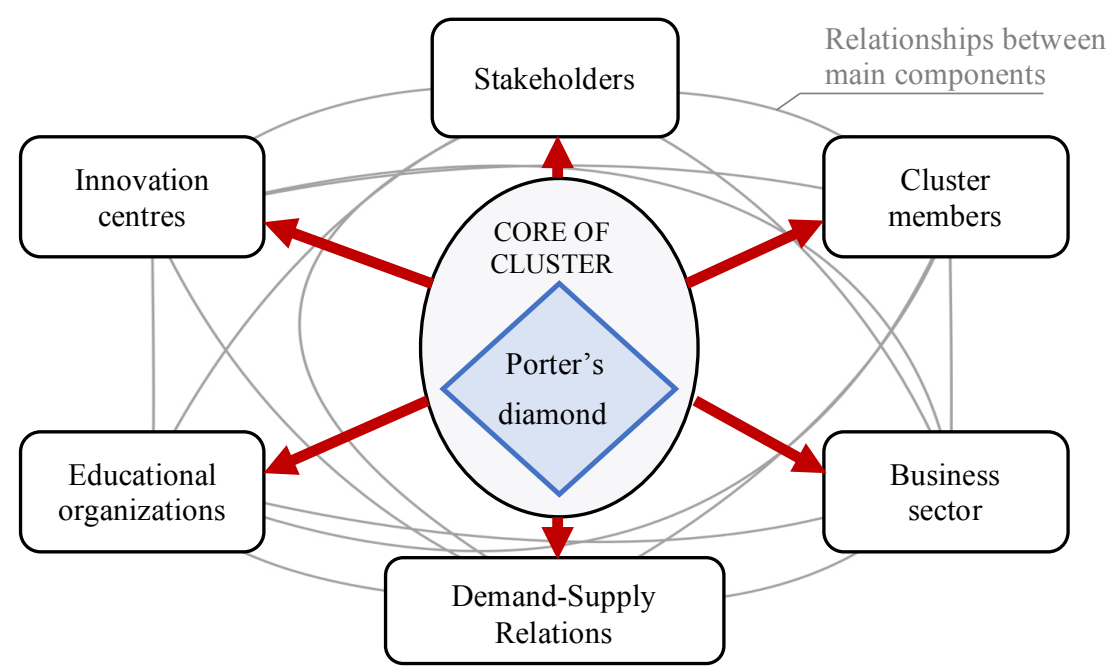

Fig. 3. Model of 6 components

Cluster as well as businesses that are grouped, carries on business. In carrying out business activities, the clusters proceed mostly in traditional way (planning, organization, implementation, evaluation and monitoring activities). According to the proposed model, the clusters should be in conducting its business activities, first to define the objectives, then carried out the activities to achieve the set objectives and evaluate the attainment of goals. Consequently, it is necessary that the findings are compared with market requirements. Finally, it needs to be adapted to the requirements of cluster activities. To the external world, cluster should perform various marketing and management activities. The main marketing activities, which should perform automotive clusters include: participation in competitions, public relations and organizations of conferences, fairs or exhibitions. Management activities are: creating projects and research in the laboratory.

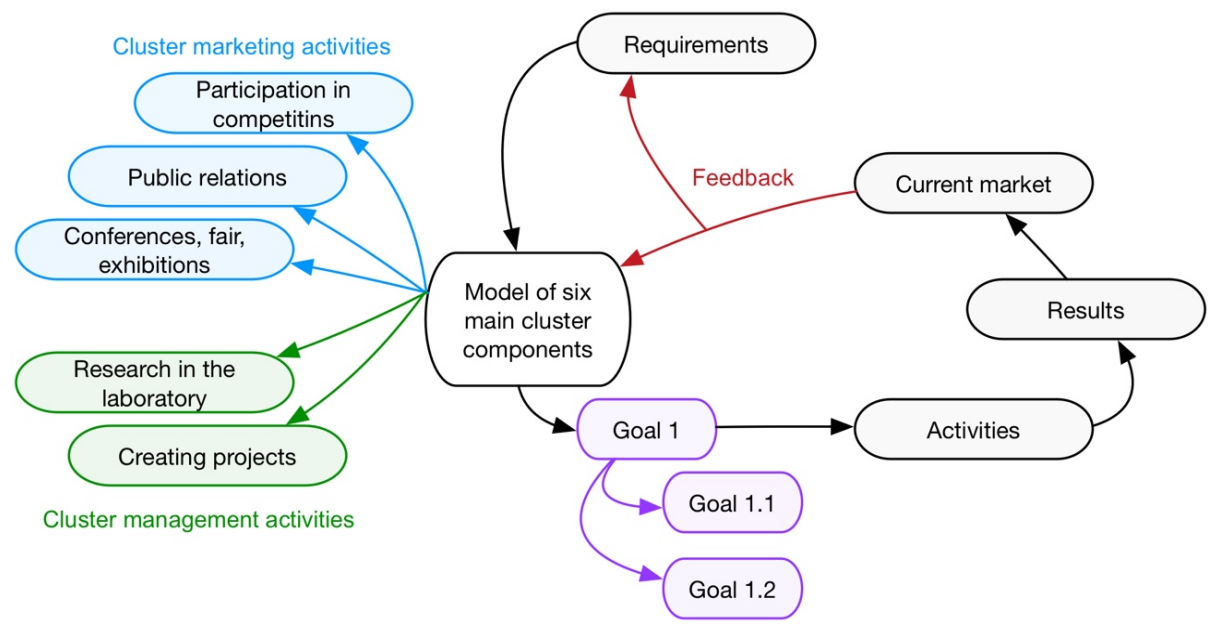

Fig. 4. Model of 6 components - expanded 


\section{The benefits, anticipated benefits, and planned effects}

Clusters bring many benefits to associated enterprises. The very small businesses by themselves could not be as successful as, where they form a single unit. By the concentration of core competencies, they form clusters of specialized suppliers and stakeholders who can collectively create a unique value and they be able to be more flexible than individual enterprises. Enterprises grouped into clusters can promptly respond to emerging changes in global markets and they can also share costs and risks that are spread to cluster members, so they are reduced. An activity that constitutes a further advantage is also non- public dissemination of knowledge among cluster members. This activity brings the better mutual education, the improving the knowledge of channels and also increasing the overall level of cluster members. The cooperation between firms in the association, so in a cluster creates a competitive advantage for the whole and for individual companies, reducing risks and costs. [10]

The introduction of this model should bring a new international contacts, expand the membership base, improve counselling for members, improve learning opportunities for members of cluster and improve the scientific and research activities of the cluster for cluster.

\section{Implementation risks}

The implementation of each model brings with it certain risks. In case of implementing the extended model were identified four main potential risks. The first risk is the negative change in the external environment. This environment can be affected by cluster positive as well as negative, such as with different laws and regulations, either in the region or abroad. The cluster can be also negatively affected by economic crisis, which may impact on the operation of the whole cluster and to its individual members. Competition, which belongs to the external environment, affects the cluster at all times, but may occur potential threat to unfair fights. The second major risk is ineffective marketing which result in a lack of membership, if it cannot attract businesses and institutions of from all main components (educational institutions, R \& D institutions and production companies). Inefficient marketing could also affect the enforcement of the cluster in foreign markets, while the companies do not achieve added value in the form of competitive advantage. The third risk is the failure to fulfil the objective / purpose of formation the cluster, namely large businesses in the cluster are at risk of stagnation, if they not engage the whole membership. By failure to comply with the objective / purpose we can expect the risk that the cluster will not be able to create your own project, or to engage in other solutions, the consequence may also be unsuccessful research and development of innovation. The last risk is the reluctance of cluster membership. The reluctance may arise in several areas - the unwillingness of communication and cooperation with other members of the cluster, also reluctance to actively participate in the project or unwillingness to share information, know-how, or producing and innovating capacities 


\section{Conclusion}

Clustering is a modern way of increasing the competitiveness of regions, companies and other institutions in its territory. Cooperation of companies associated in the cluster given the rapidly evolving markets in the future almost inevitable. There were designed two model solutions arising from the analysis of two clusters in the automotive sector. Designed models point to the need to improvement of relations between the individual components of the cluster. Model solutions have been proposed universal and therefore they are suitable for usage in various business sectors. Expansiveness of solved issues opens the way for further investigation. As part of a possible future investigation it would be interesting to think about questions such as: How to increase competitiveness of cluster? Which specific marketing and management activities will be carried out in a cluster? How could be possible to achieve synergies in cooperation in a cluster? How stakeholders have effect on the performance of the cluster? What types of system to support decision (Decision Support Systems) should be used by the cluster to gain greater competitive advantage?

\section{Acknowledgements.}

The paper was supported by the Slovak Research and Development Agency under the contract No. APVV-15-0511 and the project VEGA 1/0617/16 - Diagnosis of Specifics and Determinants in Strategic Management of Sporting Organizations.

\section{References}

1. Členstvo v ACS. Available at: http://www.autoklaster.sk/sk/clenstvo

2. Elsevier Science, (2002) Past, present, and future of decision support technology. Decision Support Systems volume 33: 111-126.

3. Harvard Business Review, (1998). Clusters and the New Economics of Competition. November-December 1998 Issue. Available at: Https://hbr.org/1998/11/clusters-and-thenew- economics-of-competition

4. Indian Journal of Computer Science and Engineering, (2011) Decision Support System is a tool for making better decisions in the organization. Volume 2. No. 1: 112-117.

5. Jaroslav Šmíd. Združovanie podnikov. Available at: Http://www.nanosvet.sk/_paper/zdruzovanie_podnikov_odvetvova_a_geograficka_blizkos t.pdf

6. Klastrovanie. Available at: https://www.siea.sk/materials/files/inovacie/slovenske _klastre/SIEA-brozura- Klastrovanie.pdf

7. Priemyselný a technologický park Trnava. Available at: http://www.trnava.sk/sk/clanok/mestsky-priemyselny-a-technologicky-park-trnava1\#sthash.V A3E8XSG.dpuf

8. Stratégia MAC. Available at: http://autoklastr.cz/strategie

9. ŠKORECOVÁ, E., Informačné technológie ako faktor konkurencieschopnosti. Available at: http://www.slpk.sk/eldo/2005/011_05/sekcia4/skoreco va.pdf 
10. Transfer inovácií, (2009). Projekt Automotive Cluster Centrope. Transfer inovácií volume 13/2009: 160-161. Available at: http://205.254.135.24/totalenergy/data/annual/pdf/aer. pdf

11. Účast' na vel'trhu ACS. Available at: http://www.autoklaster.sk/sk/news/487-veltrhhannover-messe laboratóriá

MAC.

Available

at: http://www.rozhlas.cz/ostrava/aktualne/_zprava/menza -vsb-skryva-velmi-neobvyklevedecke-laboratore-- 1106244

13. Veronika Littvová. Klastrová iniciatíva ako nástroj zvyšovania efektivity a prosperity podnikov regiónu

Liptov.

Available

at: Http://www.cutn.sk/Library/proceedings/mch_2014/ed itovane_prispevky/15.\%20Littvov\%C3\%A1.pdf

14. Vízia a ciele ACS. Available at: http://www.autoklaster.sk/sk/o-autoklastri/vizie-a- cieleautoklastra

15. Webstránka Moravsko-sliezkeho automobilového klastra. Available at: http://autoklastr.cz 